LBL-35431

UC-401

\title{
A New Association-Model for Binary VLE of Alcohol/Hydrocarbon and Amine/ \\ Hydrocarbon Mixtures
}

J. v. Schnitzler and J. M. Prausnitz

\author{
Department of Chemical Engineering \\ University of California \\ and \\ Chemical Sciences Division \\ Lawrence Berkeley Laboratory \\ University of California \\ Berkeley, CA 94720, U.S.A.
}

\section{March 1994}

This work was supported by the Director, Office of Energy Research, Office of Basic Energy Sciences, Chemical Sciences Division of the U.S. Department of Energy under Contract Number DE-AC03-76SF00098.

\section{MASTER}


Molecular Thermodynamics:

\section{A New Association-Model for Binary VLE of Alcohol / Hydrocarbon and Amine / Hydrocarbon Mixtures}

J. v. Schnitzler and J.M. Prausnitz

March 1994

Department of Chemical Engineering

University of California

Berkeley 


\section{Contents:}

Abstract

1. Introduction

2. Derivation of the Poisson-Association Model

2.1 Activity Coefficient in an Associating Solution

3. Calculations and Comparison with Experimental Data

4. Discussion and Conclusion

5. Tables

6. Figures

Appendix 1: The Poisson Distribution Function Appendix 2: Computer Program

Notation

Literature 


\begin{abstract}
An association model for binary vapor-liquid equilibria (VLE) has been developed using the Poisson distribution function to describe the relation between consecutive association reactions and their equilibrium constants. This model considers the probability of consecutive association reaction and the effect of that probability on the entropy of association.

The Poisson-distribution model is compared with a classical linearassociation model with the same number of adjustable parameters (two equilibrium constants and one physical parameter). Both models are able to represent the properties of alcohol-hydrocarbon and amine-hydrocarbon mixtures.The Poisson-distribution model, however, appears to be superior for those mixtures where the molecules of the associating component form rings rather than chains. Analysis of the VLE data provides some trends about the behavior of the model parameters with respect to temperature and molecular size of the associating component.
\end{abstract}

\title{
1. Introduction
}

The process industries have recognized for many years the importance of thermodynamic and physical properties of solutions in design calculations. Environmental problems in the form of excessively high carbon monoxide levels are attributed mostly to automotive emissions. One of the methods used to reduce $\mathrm{CO}$ emissions is the use of oxygenates such as ethanol or methanol in gasoline blends. As these blends are now of more commercial importance, it becomes necessary to understand their behavior and equilibrium characteristics to optimize the processes used for their production and handling. Therefore, thermodynamic informations in the form of vapor-liquid equilibria (VLE) are of particular interest.

Alcohol-hydrocarbon blends, for example, form associated solutions due to hydrogen bonding between the alcohol molecules. The behavior of this type of solutions has been studied by several investigators [1,7]. The most common model is the linear-association model (LAM) where the consecutive association reactions are assumed to be 'repeatable steps': All consecutive assotiation reactions are assumed to have the same equilibrium constant $\left(\mathrm{K}_{12}=\mathrm{K}_{23}=\mathrm{K}_{34}=\right.$....etc. $)$.

In contrast to this simplification, some studies have been reported [4 and 7] where the equilibrium constants depend on the degree of association. A 
good example is given by Wolff and Höpfner [4] who studied the system nHexane/Methylamine at several temperatures. Although this work is only concerned with the first three equilibrium constants of the association reaction (1), it shows that they are not the same; they increase in the order $\mathrm{K}_{12}<\mathrm{K}_{23}<\mathrm{K}_{34}$. With regard to the heat of formation of dimers, trimers and tetramers, the same value (about $1800 \mathrm{cal} / \mathrm{mol}$ ) was found. Considering the equation $-\operatorname{lnK}=\Delta \mathrm{h} / \mathrm{RT}-\Delta \mathrm{s} / \mathrm{R}$, the increase of the equilibrium constants is mainly caused by a change in the entropy term.

Usually those models where the equilibrium constant is allowed to depend on the degree of association, require a large number of adjustable parameters. The algebraic complexity is much larger than that for a LAM, unless some effort is made to find a relation between the different association constants.

\section{Derivation of the Poisson-Association Model}

We have a general association reaction

$$
A_{j}+A_{1} \Leftrightarrow A_{j+1}
$$

We give attention to the relation between an equilibrium constant of the association reaction (2.1) and its association number $\mathrm{j}$. In general, the equilibrium constant can be expressed as

$$
K_{j+1}=f(j) K
$$

where $f(j)$ is a distribution function that depends on the nature of the associating compound and $\mathrm{K}$ is a constant. We use the Poisson distribution function as discussed by Anderko and Prausnitz [8]. If constant $\mathrm{K}$ is chosen to be the equilibrium constant of the dimerization reaction (dimerization constant), then $f(j)$ must be normalized to $f(1)=1$.

As shown in Appendix 1, $\Pi(j)$, the probability that $j$ molecules form an associate $A_{j}$, can be expressed by a Poisson distribution function

$$
\Pi(j)=\frac{\kappa^{j}}{j !} e^{-\kappa}
$$


where $\mathrm{K}$ is a constant. From Eq. (2.3) we obtain an expression for $\mathrm{f}(\mathrm{j})$

$$
f(j)=\frac{\kappa^{j-1}}{j !}
$$

Equilibrium constant $K_{j, j+1}$ is then given by

$$
\mathrm{K}_{\mathrm{j}, \mathrm{j}+1}=\mathrm{K}_{1,2} \cdot \frac{\kappa^{\mathrm{j}-1}}{\mathrm{j} !}
$$

Figure 1 shows the distribution function $f(j)$ for different values of $\kappa$.

\subsection{Activity Coefficients in an Associating Solution}

We consider a component $i$ in a binary solution $(i=A, B)$ at constant temperature. In this solution component $\mathrm{A}$ can self-associate according to Equation (2.1). The second component $B$ is a solvent which does not selfassociate and does not solvate with component $\mathrm{A}$. The equation of phase equilibrium is

$$
f_{i}^{v}=f_{i}^{L}
$$

The fugacity in the vapor phase is

$$
\mathrm{f}_{\mathrm{i}}^{\mathrm{v}}=\phi_{\mathrm{i}} \cdot \mathrm{y}_{\mathrm{i}} \cdot \mathrm{P}
$$

where $\phi$ is the fugacity coefficient, $y$ is the mole fraction in the gas phase and $\mathrm{P}$ is the total pressure. At low pressure, the fugacity coefficient goes to unity. In this work we set $\phi_{\mathrm{i}}=1$.

For the liquid phase, the fugacity of component A can be written

$$
\mathrm{f}_{\mathrm{A}}^{\mathrm{L}}=\gamma_{\mathrm{A}}^{\text {chem }} \cdot \gamma_{\mathrm{A}}^{\text {phys }} \cdot \mathrm{x}_{\mathrm{A}} \cdot \mathrm{f}_{\text {pure } \mathrm{A}}^{\mathrm{L}}
$$

where $\gamma_{\text {chem }}$ is the activity coefficient caused by the self-association of component $\mathrm{A}, \gamma$ phys is the physical contribution to the activity coefficient, 
$x_{A}$ is the mole fraction of component $A$ in the liquid phase and $f_{\text {pure }} A$ is the fugacity of pure component $\mathrm{A}$, all at system temperature.

We now use the general theorem (Appendix VII of [9]) that the fugacity of an associating component $\mathrm{A}$ is equal to the fugacity of its monomer. Equation (2.8) then becomes

$$
\gamma_{\mathrm{A}}^{\text {chem }} \cdot \gamma_{\mathrm{A}}^{\text {phys }} \cdot \mathrm{x}_{\mathrm{A}} \cdot \mathrm{f}_{\text {pure } \mathrm{A}}^{\mathrm{L}}=\mathrm{z}_{\mathrm{A} 1} \cdot \mathrm{f}_{\text {pure } \mathrm{A} 1}^{\mathrm{L}}
$$

where $\mathrm{z}_{\mathrm{A} 1}$ is the 'true' mole fraction of monomer $\mathrm{A} 1$. The ratio of the two fugacities $f_{\text {pure } A} / f_{\text {pure } A l}$ can be expressed as

$$
\frac{f_{\text {pure } A}^{L}}{f_{\text {pure } A 1}^{L}}=\operatorname{limit}_{x_{A} \rightarrow 1} z_{A 1}=z_{A 1}^{0}
$$

With Eqs. (2.9) and (2.10) we obtain an expression for $\gamma_{A}{ }^{\text {chem. }}$. Provided that we also adopt an expression for $\gamma$ phys, to consider the physical interactions, caused by the different size and shape of the two molecules, we assume that

$\ln \gamma_{\mathrm{A}}^{\text {phys }}=\frac{\beta}{\mathrm{RT}} \cdot \mathrm{v}_{\mathrm{A}} \cdot \Phi_{\mathrm{B}}^{2}$ and $\ln \gamma_{\mathrm{B}}^{\text {phys }}=\frac{\beta}{\mathrm{RT}} \cdot \mathrm{v}_{\mathrm{B}} \cdot \Phi_{\mathrm{A}}^{2}$

where $v_{i}$ is the molar volume of component $i$ and the volume fractions $\Phi$ are

$\Phi_{A}=\frac{\left(v_{A} / v_{B}\right) x_{A}}{\left(v_{A} / v_{B}\right) x_{A}+x_{B}} \quad$ and $\Phi_{B}=\frac{x_{B}}{\left(v_{A} / v_{B}\right) x_{A}+x_{B}}$

Binary parameter $\beta$ reflects physical interactions between components $A$ and B. Equations (2.9)-(2.12) give the final expression for activity coefficients

$$
\begin{aligned}
& \gamma_{\mathrm{A}}=\frac{\mathrm{z}_{\mathrm{A} 1}}{\mathrm{x}_{\mathrm{A}} \cdot \mathrm{z}_{\mathrm{A} 1}^{0}} \cdot \exp \left[\frac{\beta}{\mathrm{RT}} \mathrm{v}_{\mathrm{A}}\left(\frac{\mathrm{x}_{\mathrm{B}}}{\left(\mathrm{v}_{\mathrm{A}} / \mathrm{v}_{\mathrm{B}}\right) \mathrm{x}_{\mathrm{A}}+\mathrm{x}_{\mathrm{B}}}\right)^{2}\right] \\
& \gamma_{\mathrm{B}}=\frac{\mathrm{z}_{\mathrm{B}}}{\mathrm{x}_{\mathrm{B}}} \cdot \exp \left[\frac{\beta}{\mathrm{RT}} \mathrm{v}_{\mathrm{B}}\left(\frac{\left(\mathrm{v}_{\mathrm{A}} / \mathrm{v}_{\mathrm{B}}\right) \mathrm{x}_{\mathrm{A}}}{\left(\mathrm{v}_{\mathrm{A}} / \mathrm{v}_{\mathrm{B}}\right) \mathrm{x}_{\mathrm{A}}+\mathrm{x}_{\mathrm{B}}}\right)^{2}\right]
\end{aligned}
$$


According to Equations (2.13) and (2.14) we need an expresion for $\mathrm{z}_{\mathrm{A} 1}$, $\mathrm{z}_{\mathrm{A} 1}{ }^{\circ}$ and $\mathrm{z}_{\mathrm{B}}$, which can be obtained from stoichiometry and from chemicalequilibrium relations as discussed in the next section.

\section{Calculations and Comparison with Experimental Data}

The true mole fractions of monomer $A_{1}$, either in pure $A$ or in the mixture, are obtained from stoichiometric relations

$$
z_{A j}=\frac{n_{A j}}{n_{t}}
$$

where $n_{A j}$ is the number of moles of the $j$-mer of component $A$ and $n_{t}$ is the total number of moles of component $\mathrm{A}$ and $\mathrm{B}$. From chemical equilibrium

$$
\mathrm{z}_{\mathrm{Aj}}=\mathrm{K}_{\mathrm{j}-1, \mathrm{j}} \cdot \mathrm{z}_{\mathrm{Aj}-1} \cdot \mathrm{z}_{\mathrm{A} 1} \quad \mathrm{j}=2,3, \ldots \ldots, \mathrm{m}
$$

For calculating the chemical contribution to the total nonideality of the mixture, we assume that the solution of 'true' species forms an ideal solution. From mass balances

$$
\mathrm{n}_{\mathrm{A}}=\sum_{\mathrm{j}=1}^{\mathrm{m}} \mathrm{j} \cdot \mathrm{n}_{\mathrm{Aj}} \quad \text { and } \quad \mathrm{n}_{\mathrm{t}}=\sum_{\mathrm{j}=1}^{\mathrm{m}} \mathrm{n}_{\mathrm{Aj}}+\mathrm{n}_{\mathrm{B}}
$$

where $\mathrm{m}$ is the highest degree of association; each further contribution is assumed to be negligibly small. In this work, $\mathrm{m}$ is 12 . Table 1 shows that the difference between calculations with $m=12$ and $m=14$, for the three (important) true mole fractions $\mathrm{z}_{\mathrm{A} 1}{ }^{0}, \mathrm{z}_{\mathrm{A} 1}$ and $\mathrm{z}_{\mathrm{B}}$, is always less then $10^{-5}$; in most cases it is less then $10^{-8}$.

To calculate $z_{A 1}$ and $z_{A 1}{ }^{0}$, we use a computer program which solves the set of Equations (3.1) - (3.3) simultaneously and also fits the three parameters $\mathrm{K}_{1,2}, \mathrm{~K}$ and $\beta$ to experimental data. A short description and the listing of the computer program are given in Appendix 2. 
To fit the three parameter to a specific system, we minimize the deviation of the calculated total pressure, using the relative root-mean-squared errors (rms).

\section{Comparison with Experimental Data}

The Poisson-association model is applied to alcohol / hydrocarbon and amine / hydrocarbon mixtures. All the experimental data used here satisfy the two thermodynamic consistency tests (Point test of Van Ness and Integral test of Redlich-Kister), as discussed in the guide of the tables of the data collection of Gmehling and Onken [10].

Results from the Poisson-association model are compared with those from a three-parameter linear-association model (LAM) that requires a dimerization constant $\left(\mathrm{K}_{1,2}\right)$, a polymerization constant $\left(\mathrm{K}_{2,3}\right)$ and physical parameter $\beta$. For this three-parameter LAM, Eqations (3.2) must be written:

$$
\mathrm{z}_{\mathrm{A} 2}=\mathrm{K}_{1,2} \cdot \mathrm{z}_{\mathrm{A} 1}^{2}
$$

and

$$
\mathrm{z}_{\mathrm{Aj}}=\mathrm{K}_{2,3} \cdot \mathrm{z}_{\mathrm{Aj-1}} \cdot \mathrm{z}_{\mathrm{A} 1} \quad \mathrm{j}=3,4, \ldots \ldots, 12
$$

The activity coefficients are again obtained from Equations (2.13) and (2.14).

Table 2 shows results of both models with the optimized three adjustable parameters and the root-mean-squared errors (rms P and rms y). Some illustrative examples are shown in Figures 2 to 6. 


\section{Discussion and Conclusion}

The advantage of the calculation procedure presented here is based on a computer program which solves several algebraic equations simultaneously.

Table 2 shows some trends concerning the model parameters. Poissonparameter $\kappa$ depends strongly on the system. It seems that $\kappa$ increases with decreasing temperature. Dimerization constant $\mathrm{K}_{12}$ increases slightly with decreasing temperature, as indicated by results for the system Methylamine/n-Hexane at $20,-10$ and -40 deg.C, where $K=3.6$ and $K_{12}=1.1$ $\left(20{ }^{\prime} \mathrm{C}\right), \mathrm{K}=4.5$ and $\mathrm{K}_{12}=1.4\left(-10^{\prime} \mathrm{C}\right)$ and $\mathrm{K}=5.3$ and $\mathrm{K}_{12}=1.8\left(-40{ }^{\prime} \mathrm{C}\right)$. This trend is apparent for most of the other systems. The system 1Propanol/Hexane $\left(50{ }^{\prime} \mathrm{C}\right.$ and $\left.25^{\circ} \mathrm{C}\right)$, for example, shows the same trend: with decreasing temperature, we again find an increase of $\kappa$ and $K_{12}$.

Concerning the different alcohols, $\kappa$ seems to decrease with a rise in the size of the molecules, as shown by results for Ethanol/Benzene $(50$ ' $\mathrm{C}), 2$ Propanol/Benzene $\left(50{ }^{\prime} \mathrm{C}\right)$ and Butanol/Benzene (45 'C).

In addition to the temperature and the size of the alcohol molecules, parameters $K_{1,2}, K$ and $\beta$ also depend on the type of solvent.

These are only rough trends. Unfortunately, the results also depend strongly on the quality of the experimental data. Although all of the systems studied here satisfy the criteria of the two thermodynanic consistency tests, calculated parameters for some systems depend strongly on the initial parameters of the fitting-process; for different sets of initial guesses, we get different sets of 'optimized' parameters. These systems are not listed in Table 2.

An example of 'high quality' experimental data are those from Wolff and Höpfner [4] for the system Methylamine/n-Hexane, for several temperatures. In this case, high quality means that, for almost any combination of initial guessed parameters, we converge upon the same final result for $\mathrm{K}_{1,2}, \mathrm{~K}$ and $\beta$. 


\section{Tables}

\begin{tabular}{|r|r|r|r|r|}
\hline \multicolumn{1}{|c|}{$\mathrm{K}$} & \multicolumn{1}{|c|}{$\mathrm{K}_{12}$} & \multicolumn{1}{c|}{ diff $\mathrm{zA}_{\mathrm{A}}{ }^{\mathrm{O}}$} & \multicolumn{1}{c|}{ diff $\mathrm{zA}_{\mathrm{A}}$} & \multicolumn{1}{c|}{ diff $\mathrm{zB}_{\mathrm{B}}$} \\
\hline 6.0 & 6.0 & $2.18 \mathrm{E}-06$ & $6.7 \mathrm{E}-07$ & $8.68 \mathrm{E}-06$ \\
6.0 & 5.0 & $2.29 \mathrm{E}-06$ & $6.9 \mathrm{E}-07$ & $7.74 \mathrm{E}-06$ \\
5.0 & 10.0 & $<1 \mathrm{E}-08$ & $1 \mathrm{E}-08$ & $2 \mathrm{E}-08$ \\
5.0 & 5.0 & $1 \mathrm{E}-08$ & $<1 \mathrm{E}-08$ & $1 \mathrm{E}-08$ \\
5.0 & 3.0 & $<1 \mathrm{E}-08$ & $<1 \mathrm{E}-08$ & $<1 \mathrm{E}-08$ \\
4.0 & 10.0 & $<1 \mathrm{E}-08$ & $<1 \mathrm{E}-08$ & $1 \mathrm{E}-08$ \\
4.0 & 6.0 & $<1 \mathrm{E}-08$ & $<1 \mathrm{E}-08$ & $<1 \mathrm{E}-08$ \\
4.0 & 4.0 & $<1 \mathrm{E}-08$ & $<1 \mathrm{E}-08$ & $<1 \mathrm{E}-08$ \\
4.0 & 2.0 & $<1 \mathrm{E}-08$ & $<1 \mathrm{E}-08$ & $<1 \mathrm{E}-08$ \\
3.0 & 3.0 & $<1 \mathrm{E}-08$ & $<1 \mathrm{E}-08$ & $<1 \mathrm{E}-08$ \\
\hline
\end{tabular}

Table 1: Differences of the true mole fractions $z_{A 1} 0, z_{A 1}$ and $z_{B}$ for calculations with $\mathrm{m}=12$ and $\mathrm{m}=14$

\begin{tabular}{|c|c|c|c|c|c|c|c|c|c|c|}
\hline & $\boldsymbol{x}$ & $K 12$ & $\beta$ & ms P & ms y & $K 12$ & K23 & $\beta$ & $m s P$ & $m s y$ \\
\hline System (lemperature, deg $C$ ) & 1 & 1 & (cal/moll) & $\left(10^{n}-3\right)$ & $\left(10^{n}-3\right)$ & 1 & 1 & (cal/moll & $\left(10^{n}-3\right)$ & $\left(10^{n} \cdot 3\right)$ \\
\hline Methanol/Benzene (45) & 6.0 & 6.5 & 170.9 & 2.24 & 6.71 & 6.1 & 14.5 & 102.6 & 3.25 & 7.32 \\
\hline Ethanol/Trimethylpentane $(50)$ & 5.5 & 5.3 & 119.0 & 2.81 & 3.45 & 6.0 & 16.4 & 106.9 & 2.88 & 3.26 \\
\hline Eihanol/Hexane (40) & 5.7 & 5.5 & 191.2 & 2.06 & 4.54 & 6.7 & 20.9 & 115.0 & 4.03 & 5.79 \\
\hline Ethanol/Cyclohexane (25) & 6.0 & 6.9 & 130.5 & 2.36 & 8.90 & 3.5 & 24.7 & 111.0 & 4.55 & 10.30 \\
\hline Ethanol/Benzene $(50)$ & 4.6 & 5.6 & 155.0 & 2.53 & 7.53 & 4.2 & 5.4 & 133.5 & 3.29 & 9.39 \\
\hline Ethanol/Toluene (35) & 4.6 & 6.8 & 110.3 & 2.77 & 4.37 & 4.6 & 5.8 & 161.8 & 3.37 & 10.20 \\
\hline 1-Propanol/Hexane (25) & 5.3 & 8.2 & 122.5 & 0.91 & 0.51 & 14.1 & 13.6 & 103.5 & 5.63 & 1.07 \\
\hline 1-Propanol/Hexane (50) & 4.3 & 6.6 & 169.7 & 5.96 & 3.65 & 6.1 & 7.1 & 184.6 & 9.85 & 6.39 \\
\hline 1-PropanovBenzene $(60)$ & 2.8 & 6.4 & 151.1 & 2.61 & 5.24 & 9.4 & 5.0 & 112.3 & 5.88 & 9.37 \\
\hline 1-Propanol/Benzene (25) & 3.3 & 7.2 & 178.5 & 3.20 & 1.50 & 14.6 & 6.1 & 178.8 & 1.92 & 0.90 \\
\hline 2-Propanol/Benzene (50) & 3.0 & 7.1 & 143.3 & 1.77 & 2.70 & 12.6 & 4.9 & 152.5 & 3.61 & 5.39 \\
\hline 1-Butanol/Benzene (45) & 3.0 & 6.0 & 107.1 & 7.80 & 1.61 & 14.9 & 3.8 & 170.9 & 8.88 & 1.82 \\
\hline 1-Butanol/Toluene $(100)$ & 2.2 & 4.7 & 107.6 & 1.63 & 6.00 & 9.2 & 1.4 & 154.5 & 1.66 & 5.99 \\
\hline 2-Butanol/Toluene $(60)$ & 2.4 & 5.1 & 106.1 & 2.11 & 3.23 & 4.5 & 2.0 & 139.4 & 5.00 & 9.62 \\
\hline 2-Butanol/Heptane (65) & 2.9 & 5.1 & 110.2 & 2.61 & 7.58 & 4.2 & 4.1 & 131.1 & 7.37 & 10.20 \\
\hline Methylamine/n-Hexane $(-40)$ & 5.3 & 1.8 & 199.8 & 1.65 & 0.19 & 3.8 & 7.6 & 196.4 & 4.83 & 0.56 \\
\hline Methylamine/n-Hexane $(-10)$ & 4.5 & 1.4 & 203.6 & 1.26 & 1.09 & 2.0 & 3.5 & 209.3 & 4.01 & 2.37 \\
\hline Methylamine/n-Hexane (20) & 3.6 & 1.1 & 230.0 & 2.30 & 1.68 & 1.6 & 1.9 & 178.1 & 4.08 & 1.35 \\
\hline & & & & & & & & & & \\
\hline & & & Poisson & & & & & \multicolumn{2}{|c|}{ 3-parameter LAM } & \\
\hline & & & & & & & & & & \\
\hline
\end{tabular}

Table 2: Parameters for the Poisson model and for the LAM model, including the relative root-mean-squared errors (rms) 


\section{Figures}

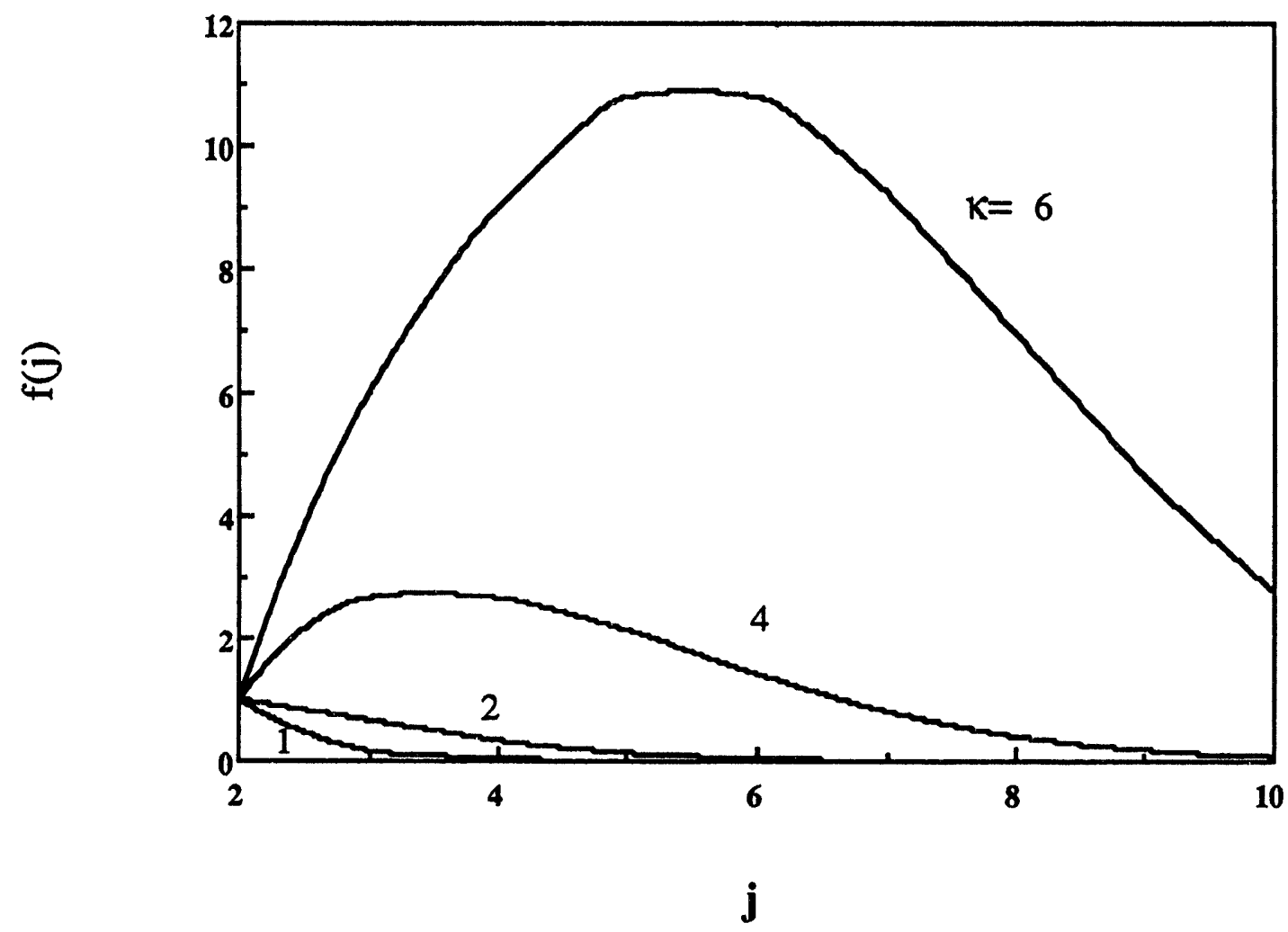

Figure 1: Distribution function $f(j)$ as a function of $j$ and parameter $k$. 

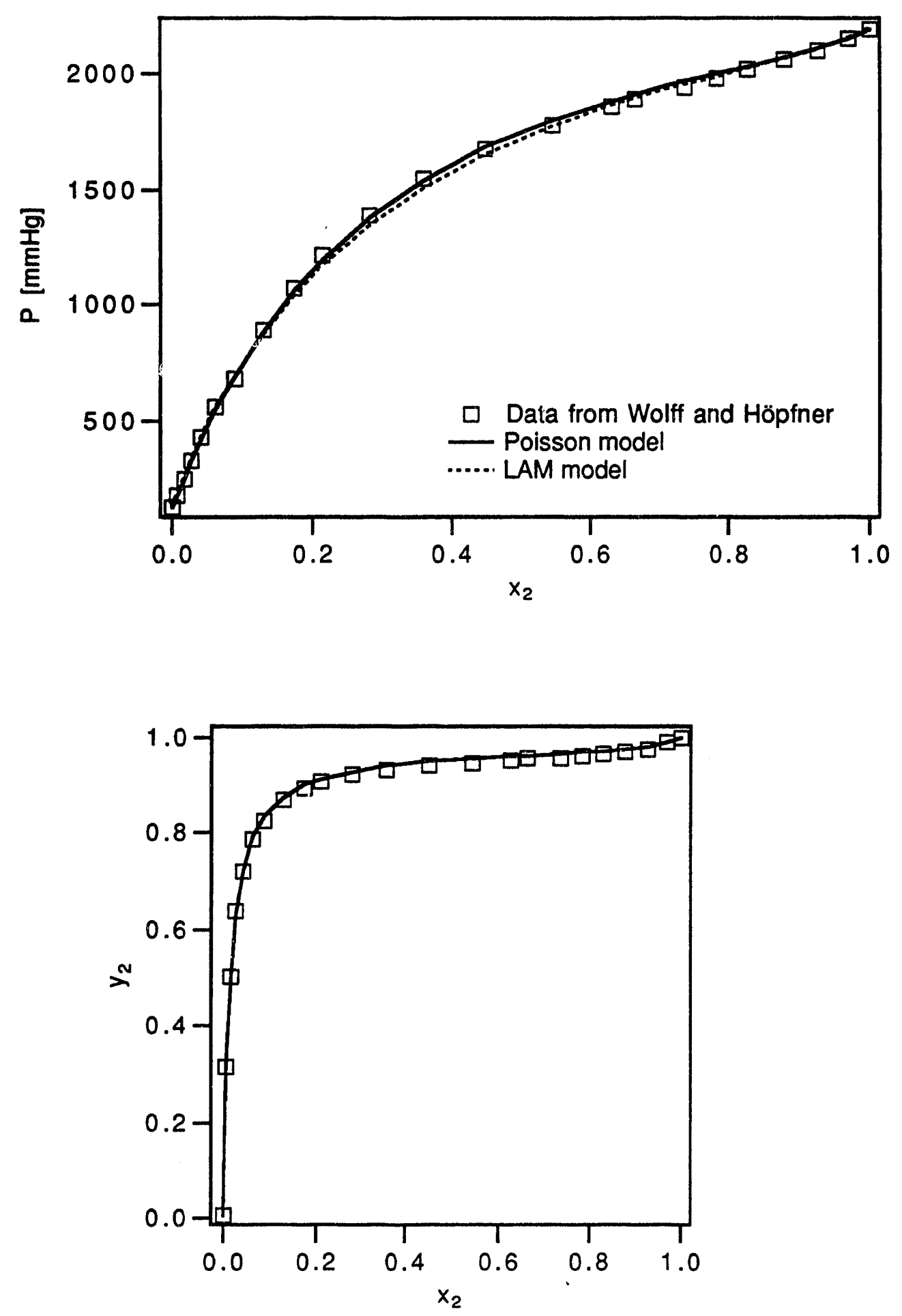

Figure 2: n-Hexane (1) / Methylamine (2), 20 ' C

Parameter: Poisson $K=3.6, \mathrm{~K}_{12}=1.1, \beta=230.0 \mathrm{cal} / \mathrm{mol}$

LAM $\quad \mathrm{K}_{12}=1.6, \mathrm{~K}_{23}=1.9, \beta=178.1 \mathrm{cal} / \mathrm{mol}$ 

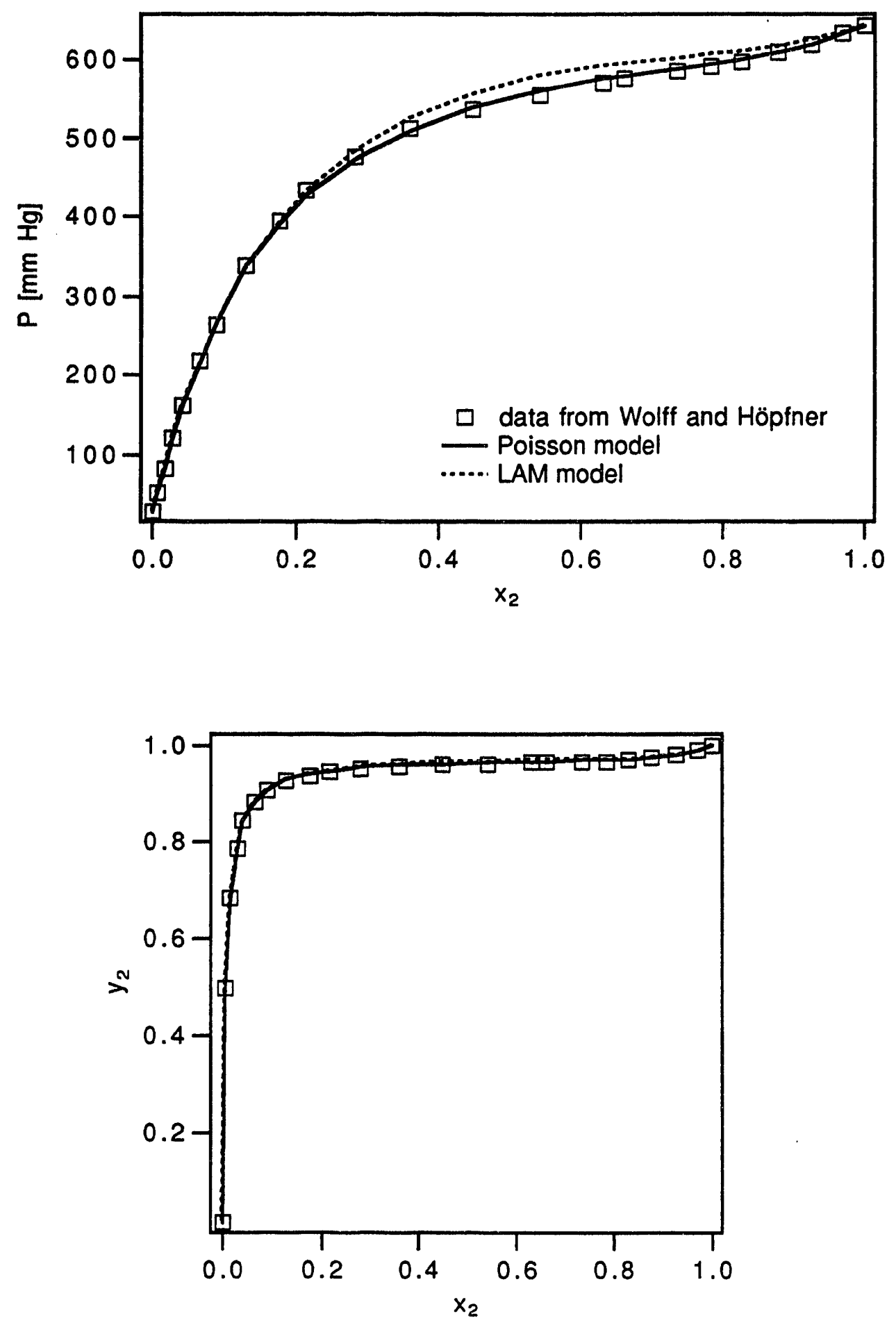

Figure 3: n-Hexane (1) / Methylamine (2), -10 'C

Parameter: Poisson $\kappa=4.5, \mathrm{~K}_{12}=1.4, \beta=203.6 \mathrm{cal} / \mathrm{mol}$ LAM $\quad \mathrm{K}_{12}=2.0, \mathrm{~K}_{23}=3.5, \beta=20.9 .3 \mathrm{cal} / \mathrm{mol}$ 

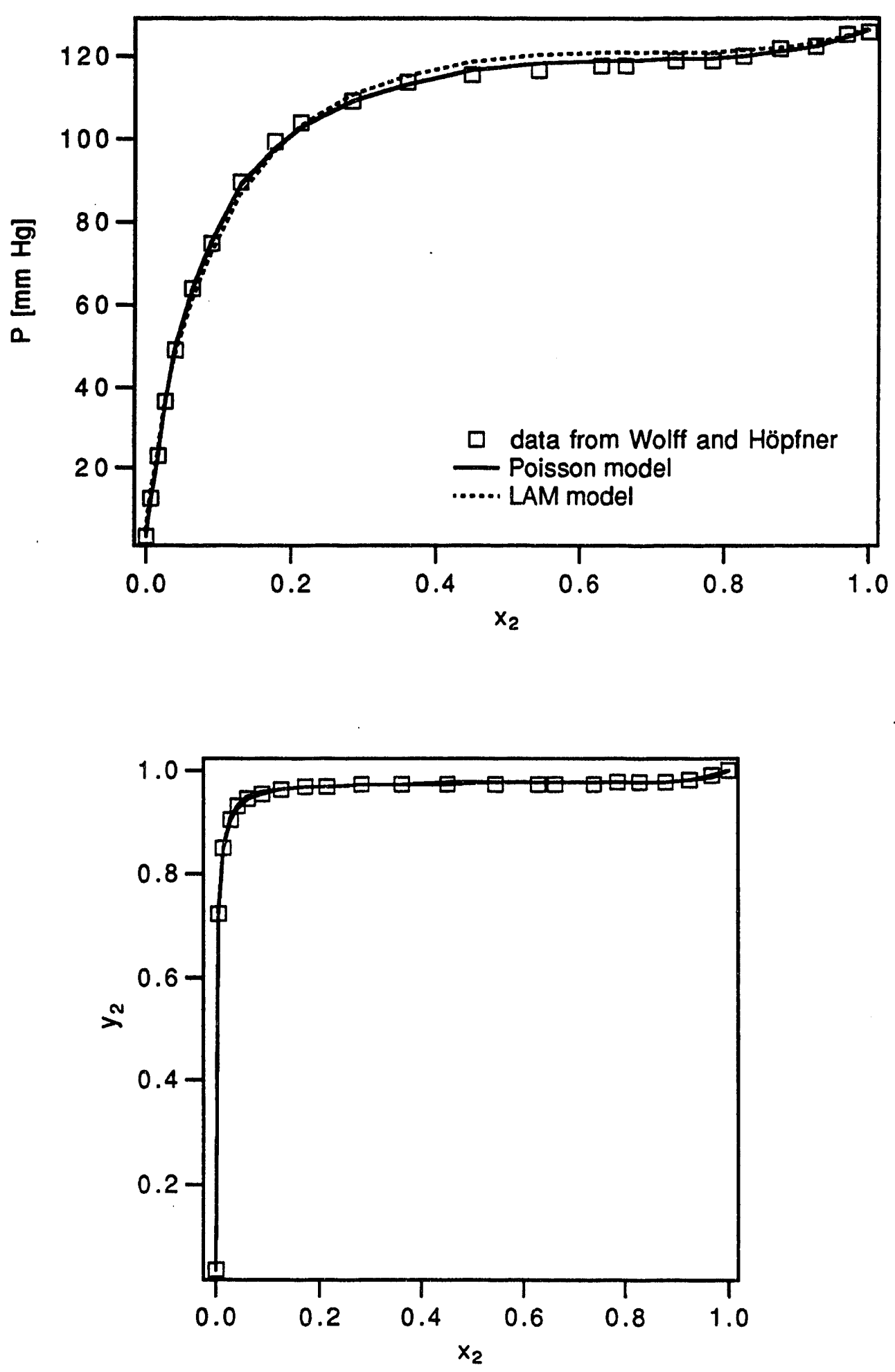

Figure 4: n-Hexane (1) / Methylamine (2), $-40^{\prime} \mathrm{C}$

Parameter: Poisson $K=5.3, K_{12}=1.8, \beta=199.8 \mathrm{cal} / \mathrm{mol}$

LAM $\quad \mathrm{K}_{12}=3.8, \mathrm{~K}_{23}=7.6, \beta=196.4 \mathrm{cal} / \mathrm{mol}$ 

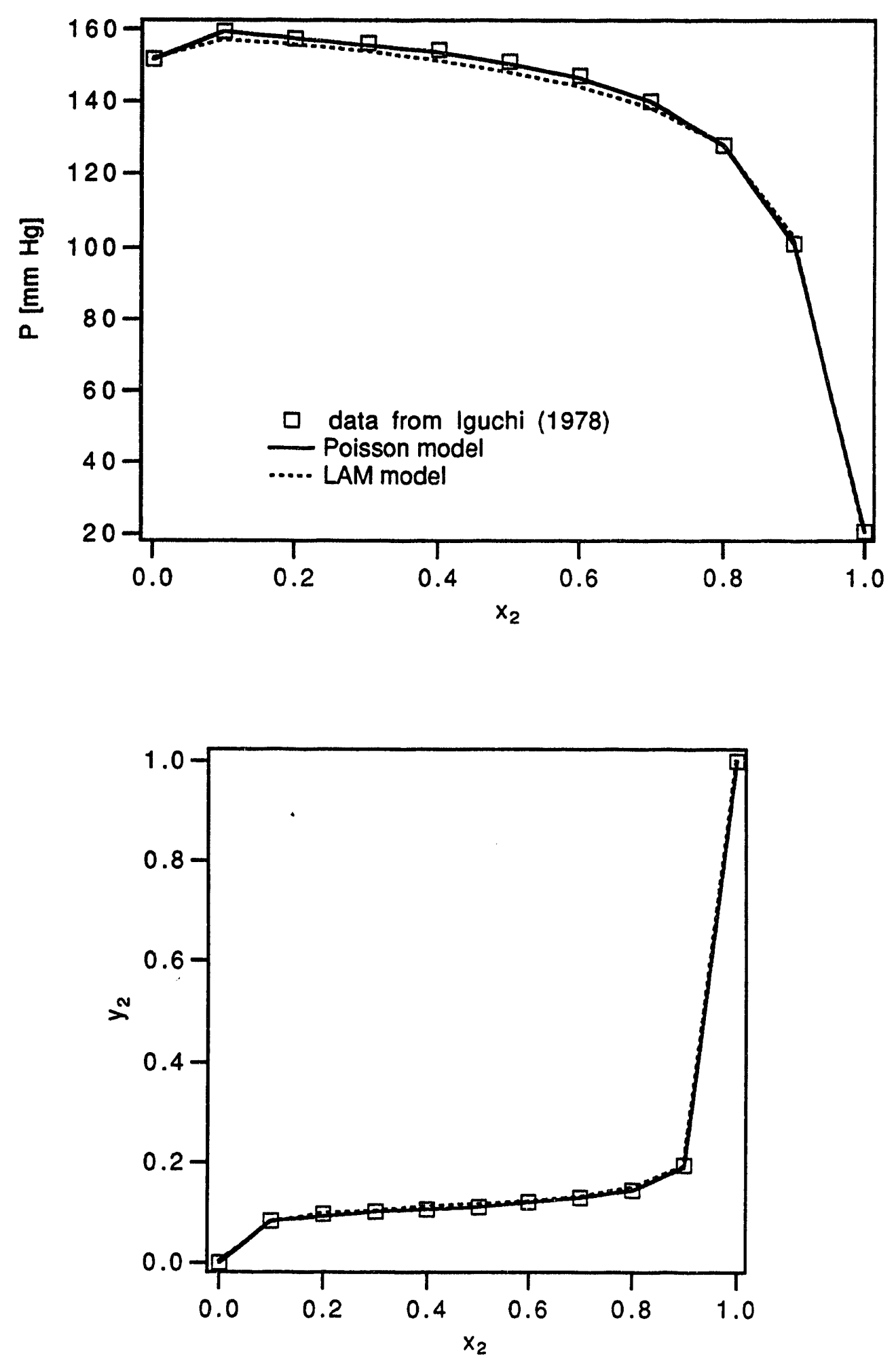

Figure 5: Hexane (1)/1-Propanol (2), $25^{\prime} \mathrm{C}$

Parameter: Poisson $\kappa=5.3, K_{12}=8.2, \beta=122.5 \mathrm{cal} / \mathrm{mol}$

LAM $\quad \mathrm{K}_{12}=14.1, \mathrm{~K}_{23}=13.6, \beta=103.5 \mathrm{cal} / \mathrm{mol}$ 

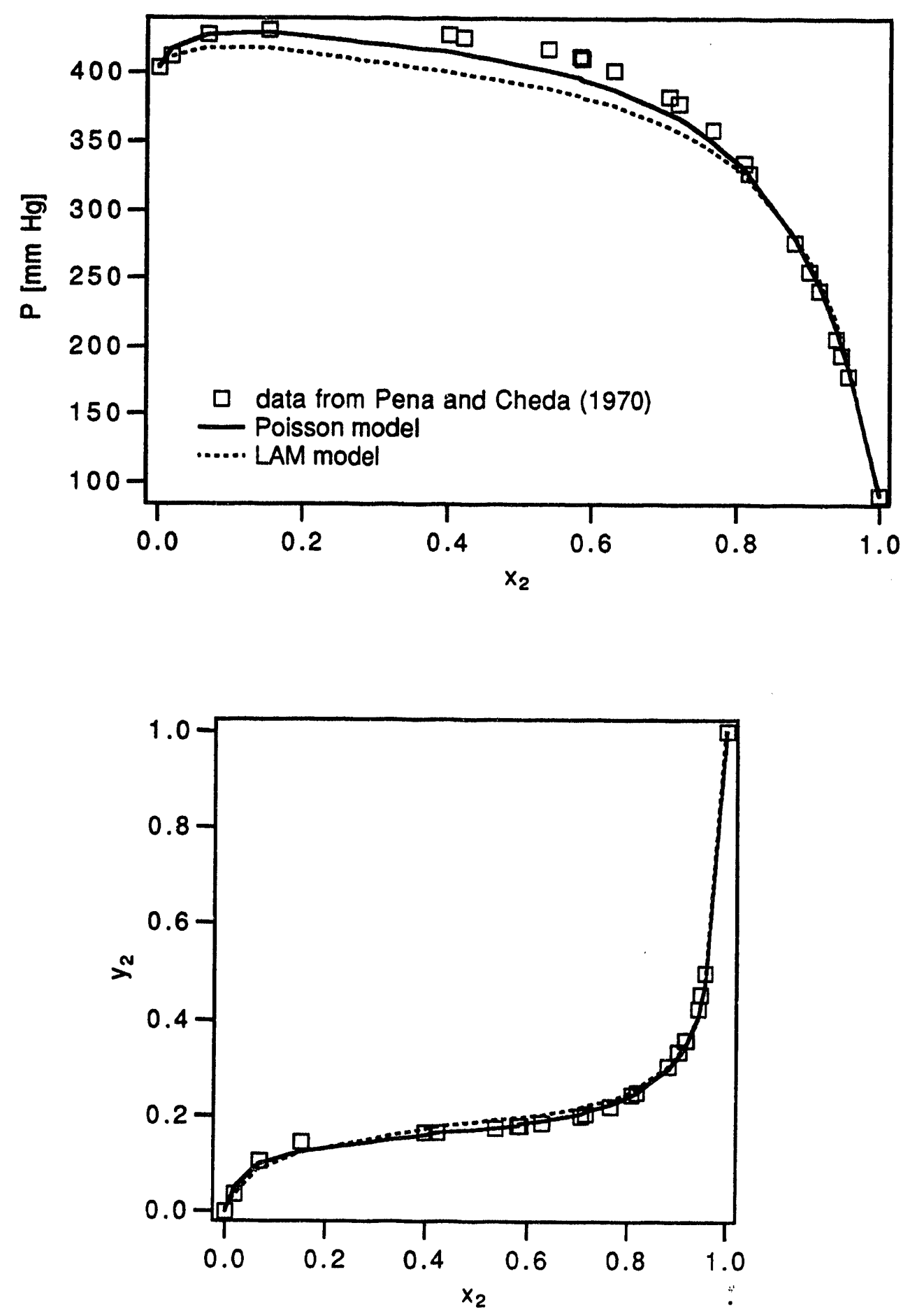

Figure 6: Hexane (1) / 1-Propanol (2), $50{ }^{\prime} \mathrm{C}$

$\begin{array}{lll}\text { Parameter: } & \text { Poisson } & \kappa=4.3, K_{12}=6.6, \beta=169.7 \mathrm{cal} / \mathrm{mol} \\ & \text { LAM } & \mathrm{K}_{12}=6.1, \mathrm{~K}_{23}=7.1, \beta=184.6 \mathrm{cal} / \mathrm{mol}\end{array}$ 


\section{Appendix 1}

\section{The Poisson Distribution Function}

Following Anderko [8], we assume that a central molecule is surrounded by $\mathbf{n}$ molecules and $\mathbf{p}$ is the probability that another molecule will join the central one to form an associate. We assume further that this probability is the same for all $\mathrm{n}$ molecules and they are independent from each other. Therefore, $\Pi(j)$, the probability that $j$ molecules will join the central one to form an associate $A_{j}$, is given by the binomial distribution:

$$
\Pi(j)=\left(\begin{array}{l}
n \\
j
\end{array}\right) p^{j}(1-p)^{n-j}
$$

We assume that $\mathrm{n}$ is a large but finite number and $\mathrm{p}$ is necessarily between zero and unity. Thus, the conditions that are necessary to apply the Poisson distribution are satisfied and eq. (A1.1) can be simplified to

$$
\Pi(j)=\frac{(n p)^{j}}{j !} e^{-n p}=\frac{\kappa^{j}}{j !} e^{-\kappa}
$$

where $\kappa$ is the product (np).

The entropy change for the association reaction (2.1) can be written as

$$
\Delta s_{j, j+1}=\Delta s^{+}+R \ln \left[\frac{\kappa^{j}}{j !}\right]
$$

where $\Delta s^{+}$is the component of the association entropy that is not related to the size of the multimer. Therefore, the Gibbs energy of change of reaction (2.1) is

$$
\begin{aligned}
\Delta \mathrm{g}_{\mathrm{j}, \mathrm{j}+1} & =\Delta \mathrm{h}_{\mathrm{j}, \mathrm{j}+1}-\mathrm{T} \Delta \mathrm{s}^{+}=\Delta \mathrm{h}^{+}-\mathrm{T} \Delta \mathrm{s}^{+}-\mathrm{RT} \ln \left[\frac{\kappa^{\mathrm{j}}}{\mathrm{j} !}\right] \\
& =\Delta \mathrm{g}^{+}-\mathrm{RT} \ln \left[\frac{\kappa^{\mathrm{j}}}{\mathrm{j} !}\right]
\end{aligned}
$$


And

$$
\Delta g_{j, j+1}=-R T \ln K_{j, j+1}
$$

The consecutive association constant $\mathrm{K}_{\mathrm{j}, \mathrm{j}+1}$ then becomes

$$
\mathrm{K}_{\mathrm{j}, \mathrm{j}+1}=\exp \left[-\frac{\Delta \mathrm{g}^{+}}{\mathrm{RT}}\right] \cdot \frac{\kappa^{\mathrm{j}}}{\mathrm{j} !}
$$

For normalization it is convenient to introduce the dimerization constant $\mathrm{K}_{1,2}=\mathrm{K}$

$$
\mathrm{K}_{1,2}=\exp \left[-\frac{\Delta \mathrm{g}^{+}}{\mathrm{RT}}\right] \cdot \kappa
$$

The distribution function $f(j)$ then becomes

$$
f(i)=\frac{\kappa^{j-1}}{j !}
$$

and Equation (A1.6) can be written

$$
K_{j, j+1}=K_{1,2} \cdot \frac{\kappa^{j-1}}{j !}
$$




\section{Appendix 2:}

\section{Computer Program}

The computer program is written in Fortran 77. It contains the mainprogram ACTIVITY COEFFICIENT and four subroutines. It also uses some 'canned' equation-solver programs from the MINPACK-1 package. This is a package of Fortran subprograms for numerical solution of systems of nonlinear equations and nonlinear least-squares problems.

The main program ACTIVITY COEFFICIENT reads the initial guesses for the model parameter, the system constants $\left(v_{A}, v_{B}, P_{A}{ }^{0}, P_{B} 0\right.$ and the number of experimental data 1$)$ and the experimental data ( $P, x$ and $y)$. Further, the main program calls the subprogram LMDIF. This MINPACK1 subprogram LMDIF varies the three model parameter and minimizes an 'user-defined' function, which is, in our case, the deviation of the calculated pressure.

This user-defined function is placed in the first subroutine FUNC. Further, FUNC contains the model equations for the calculation of the equilibrium constants $\mathrm{K}_{\mathrm{j}, \mathrm{j}+1}$ and it calls the subroutine FCNAL, for calculating the true mole fraction of the pure associating component $\left(\mathrm{x}_{\mathrm{blal}}\right)$, and the subroutine $\mathrm{FCN}$, for calculating the true mole fraction of the mixture $\left(\mathrm{x}_{\mathrm{A} 1}\right.$ and $\left.\mathrm{x}_{\mathrm{B} 1}\right)$.

Finally, FUNC calculates the output data, the activity coefficients (gamaA and gamaB), the pressure (Pcal) and the mole fraction of the vapor phase (ycal); (the mole frations of the liquid phase are given from the experimental data).

The subroutine FCNAL contains the equations (3.1) to (3.3) for the case of the pure association component. The equation solver for these equations is HYBRD1, from the MINPACK-1 package.

The subroutine FCN, together with its subroutine REGFAL is an equation solver, especially written to solve equations (3.1) to (3.3) for the mixture. It is so designed, that it starts at $\mathrm{XB}=1$ (pure associating component); it uses the solution of HYBRD1 (FCNAL) $\mathrm{x}_{\mathrm{b} 1 \mathrm{al}}$ as initial guess. From this point $(X B=1)$, the subroutine FCN searches stepwise to the next solutions for the next given mole fraction from the input file (going from $X B=1$ to $X B=0$ (pure solvent $\mathrm{A})$ ).

An example of the input file, the control files and an output file is attached. 


\section{Notation:}
A associating component
B solvent
f fugacity
$f(j)$ distribution function
h enthalpy
$\mathrm{j}$ degree of association
$\mathbf{K}_{\mathbf{j} \mathbf{j}+1}$ equilibrium constant of the consecutive association reactions
$\mathrm{m}$ highest degree of association
$n$ number of moles
p probability
$\mathrm{P}$ total pressure
$R$ general gas constant
$S$ entropy
T absolute temperature
U internal energy
$v$ molar volume
$\mathrm{x}$ mole fraction in liquid phase
$y$ mole fraction in gas phase
$z$ true mole fraction in liquid phase

\section{Greek letters:}

$\boldsymbol{\beta}$ physical parameter of the Poisson model

$\Phi$ volume fraction

$\phi$ fugacity coefficient

$\gamma \quad$ activity coefficient

$\kappa \quad$ Poisson distribution parameter 


\section{Literature:}

[1] P.J. Flory, Thermodynamics of Heterogeneous Polymers and Their Solutions, J. Chem. Phys., Vol. 12, No. 11, 425 (1944)

[2] O. Redlich, A.T. Kister, On the Thermodynamics of Nonelectrolyte Solutions and Its Technical Applications, J. Chem. Phys., Vol. 15, No. 12, 849 (1947)

[3] C.B. Kretschmer, R. Wiebe, Thermodynamics of AlcoholHydrocarbon Mixtures, J. Chem. Phys., Vol.22, No. 10, 1697 (1954)

[4] H. Wolff, A. Höpfner, Die Wasserstoffbrückenassoziation von Methylamin in n-Hexan, Z. Elektrochem., 66, 149 (1962)

[5] H.C. Van Ness, J. Van Winkle, H.B. Hollinger, Infrared Spectra and the Thermodynamics of Alcohol-Hydrocorbon Systems, J. Phys. Chem., Vol. 71, No. 5, 1483 (1967)

[6] H. Renon, J.M. Prausnitz, On the Thermodynamics of AlkoholHydrocarbon Solutions, Chem. Eng. Sci., Vol. 22, 229 (1967); Errata, 1891 (1967)

[7] E. Tucker, and E.Lippert, The Hydrogen Bond: Recent Developments in Theory and Experiment, Chapter 17.,Amsterdam: North-Holland Publishing Company (1976)

[8] A.Anderko, J.M. Prausnitz, On the Relationship Between the Equilibrium Constants of Consecutive Association Reactions, LBLReport-34023, UC Berkeley(1993). Fluid Phase Equilibria (in press,1994)

[9] J.M. Prausnitz, R.N. Lichtenthaler, E.G. de Azevedo, Molecular Thermodynamics of Fluid-Phase Equilibria, Prentice-Hall (1986)

[10] J. Gmehling, U. Onken, Vapor-Liquid Equilibrium Data Collection, DECHEMA Chemistry Data Series, Vol. 1, Part 2a (1977) 


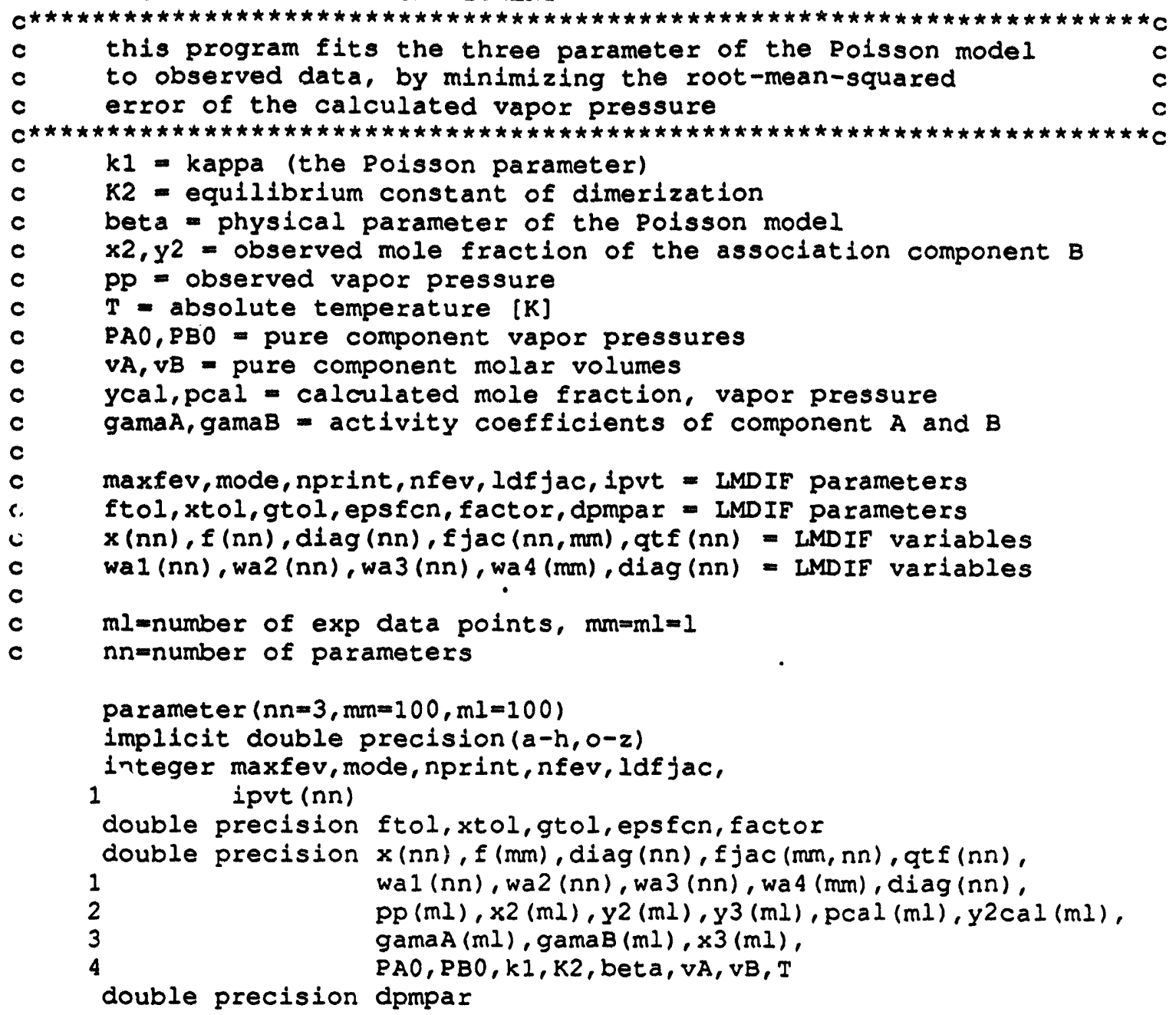

character 100 infile, infile2, outfile, infofile

character*75 name

external func

common/plock1/pp, x2, y2

common/block2/pcal, y2cal, gamaA, gamaB

common/block3/T,pa0,pb0

common/block $4 / k 1, k 2, v A, v B$, beta

common/block7/infile2

open (unit $=9, \mathrm{f} i l \mathrm{e}^{\prime}$ ' run. $c t l^{\prime}$, status=' unknown') $\operatorname{read}(9, *)$ infile $\operatorname{read}(9, *)$ infile 2

$\operatorname{read}(9, *)$ outfile

close (9) $\operatorname{read}(9, *)$ infofile

input: read in the model parameters (initial guesses) and system constants

open (unit $=10$, file=infile, status='unknown')

$\operatorname{read}\left(10, '(A)^{\prime}\right)$ name

$\operatorname{read}(10, *)$ beta

$\operatorname{read}(10, *) \cup A, v B$

$\operatorname{read}(10, *) \mathrm{k} 1, \mathrm{~K} 2$

$\operatorname{read}(10, *) \mathrm{T}$

$\operatorname{read}(10, *) \mathrm{PAO}$

$\operatorname{read}(10, *) \mathrm{PBO}$

$\operatorname{read}\left(10,{ }^{*}\right) 1$

physical parameter

molar volume of $A$ and $B$

! two parameters from the Poisson model

! constant system temperature

! vapor pressure of pure $A$

! vapor pressure of pure $B$

! number of exp data points 
c

input: experimental data

do $i=1,1$ $\operatorname{read}(10, *) \operatorname{pp}(1), \times 2(i), y^{2}(i)$

endido

close (10)

open (unit $=11$, file=outfile, status=' unknown')

c

c

c

c

number of parameters to be optimized

$n=n n$

c total nuber of functions to be minimized

$m=1$

convergenz and toleranz parameters of IMDIF

ftol=dsqrt (dpmpar (1))

$x t 01=d s q x t(d p m p a r(1))$

gtol $=0.0 \mathrm{do}$

Idf $j a c=100$

$\max f e v=600$

eps $f(n=1.0 d-5$

factor $=1.0 d+1$

mode $=1$

nprint $=1$

$x(1)=k 1$

$x(2)=k 2$

$x(3)=$ bet $a$

call lmaif (func, $1, n, x, f, f t o l, x t o l, g t o l, m a x f e v$, epsfcn, diag, mode, 1

2 factor, nprint, infof, nfev, fjac, ldfjac, ipvt, qtf, wal, wa2, wa 3, wa4)

$\mathrm{k} 1=\mathrm{x}(1)$

$\mathrm{k} 2=\mathrm{x}(2)$

bet $a=x(3) * 1.99 * T$

write $(6, *)$ ' infof $=$ ', infof

write $(11, *)$ name

write $(11, *)$

write $(11, *)$, POISSON-DISTRIBUTION MODEL'

write $(11, *)$

write $(11,120) \mathrm{kl}$

120 format ('k1 $\mathrm{k} 1, f 7.3, '$ (Poisson distribution const.)') write $(11,121) \mathrm{k} 2$

121 format ('K2=',f7.3,' (dimerization const.)')

write $(11,122)$ beta

122 format ('beta $=$ ', $f 7.3$, ' [cal/mol]')

write $(11,123) v A, v B$

123 format ('v1 $=\prime, f 5.2, ', \quad v 2=\prime, f 5.2,,^{\prime}$ (molar.volumes)') write $(11,150) \mathrm{T}$

150 format ('Temperature $\left.=\prime, f 5.1,{ }^{\prime}[\mathrm{K}]^{\prime}\right)$

write $(11, *)$

write $(11,170)$

170 format ('P [mmHg]',5x,' $x 2^{\prime}, 8 x, y^{\prime} 2^{\prime}, 8 x,,^{\prime} P$ calc', 5x, $y 2$ calc') write $(11, *)$ ' 
do $i=1,1$

$y^{3}(1)=1-y^{2}(i)$

$x 3(1)=1-x 2(1)$

enddo

write $(11,200) \mathrm{pp}(1), \mathrm{x} 3$ (i), y3 (i), pcal(i), y2cal (i)

200 format ( $f 7.2,5 x, f 6.4,5 x, f 6.4,4 x, f 7.2,5 x, f 6.4$ )

c calculate root mean squared error of pcal and ycal

ssqp $=0.0 \mathrm{do}$

$s \mathbf{s q}=0.0 \mathrm{do}$

do $1=1,1$

enddo

$s s q p=s s q p+((p p(i)-p c a l(i)) / P P(i)) * * 2$

do $i=1,1$ enddo

$s s q y=s s q y+\left(\left(y^{2}(i)-y^{2} \operatorname{cal}(i)\right) / y^{2}(i)\right) \star \star 2$

rmsp $=\operatorname{dsqrt}($ (ssqp) /float (1))

rmsy = dsqrt ( (ssqy) /float (1))

write $(11, \star)$ '

write $(11, *)$

write $(11, *)$ 'relative rms error vap pressure = ', real(rmsp)

write $(11, *)$ 'relative rms error mole fract. =', real (rmsy)

close (11)

end 
SUBROUTINE func $(1, n, x, f, i f l$ ag)

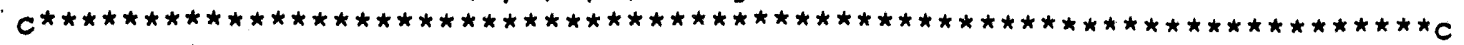

c This subroutine calculates the residuals of the function $c$

c to be minimized

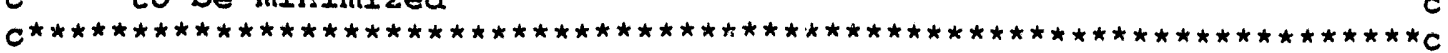

C $\quad X A, X B=$ mole fractions of compponents $A$ (1) and $B$ (2)

$C \quad x a 1, x b 1=$ true mole fractions of the monomers of $A$ and $B$

c $\quad x b l a l=$ true mole fraction of associating component $B$

$f(i)=$ function to be minimized

$w(i)=$ variables for the true mole fractions

nal, infocc, tol, lwa = HYBRID1 parameters

wa, fvecal = HYBRID1 variables

parameter $(n n=3, n k=12, m m=100, m l=100)$

implicit double precision $(a-h, 0-z)$

integer. nal, infocc, lwa

double precision $x(n n), f(m m), p p(m l), x 2(m l), y 2(m l), w(2)$, 1

2

3 pcal (ml), y2cal (ml), gamaA (ml), gamaB (ml), wa $(500)$, fvecal (1), $K(n k)$, $k 1, K 2, X A, X B, v A, v B$, beta

character*100 infile 2

external fonal, fon

common/block1/pp, $x 2, y^{2}$

common/block2/pcal, y2cal, gamaA, gamaB

common/block3/T, paO, pb0

common/block4/k1, K2, VA, vB, beta

common/block $5 / \mathrm{K}$

common/block6/XA, XB

common/block7/infile2

initial guesses for the parameters

$k 1=x(1)$

$\mathrm{K} 2=\mathrm{x}(2)$

bet $a=x(3)$

do $i=1, n n$

if $(x(i) .1 e \cdot 0.0 d 0)$ then

do $j=1,1$

enddo

$f(j)=10000$

endif

enddo

goto 99

write $(6, *)^{\prime} k 1=\prime, x(1)$

write $(6,)^{\prime} \mathrm{K} 2={ }^{\prime}, \mathrm{x}(2)$

write $(6, *)$ 'bet $a={ }^{\prime}, x(3)$

c

calculation of the equilibrium constants of the $n$-mers

$K(2)=K 2$

$K(3)=k 1 * \star 2 / 6 . \star k 2$

$K(4)=k 1 * \star 3 / 24 . * K 2$

$K(5)=k 1 * \star 4 / 120 * k 2$

$K(6)=k 1 * \star 5 / 720 . \star K 2$

$\mathrm{K}(7)=\mathrm{k} 1 * \star 6 / 5040 . \star \mathrm{K} 2$

$K(8)=k 1 * * 7 / 40320 .{ }^{*} 2$

$K(9)=k 1 * \star 8 / 362880 . * K 2$

$\mathrm{K}(10)=\mathrm{k} 1 * \star 9 / 3628800 .{ }^{*} \mathrm{~K} 2$

$K(11)=k 1 * \star 10 / 39916800 * * K 2$

$K(12)=k 1 * \star 11 / 479001600 * *^{*} 2$ 


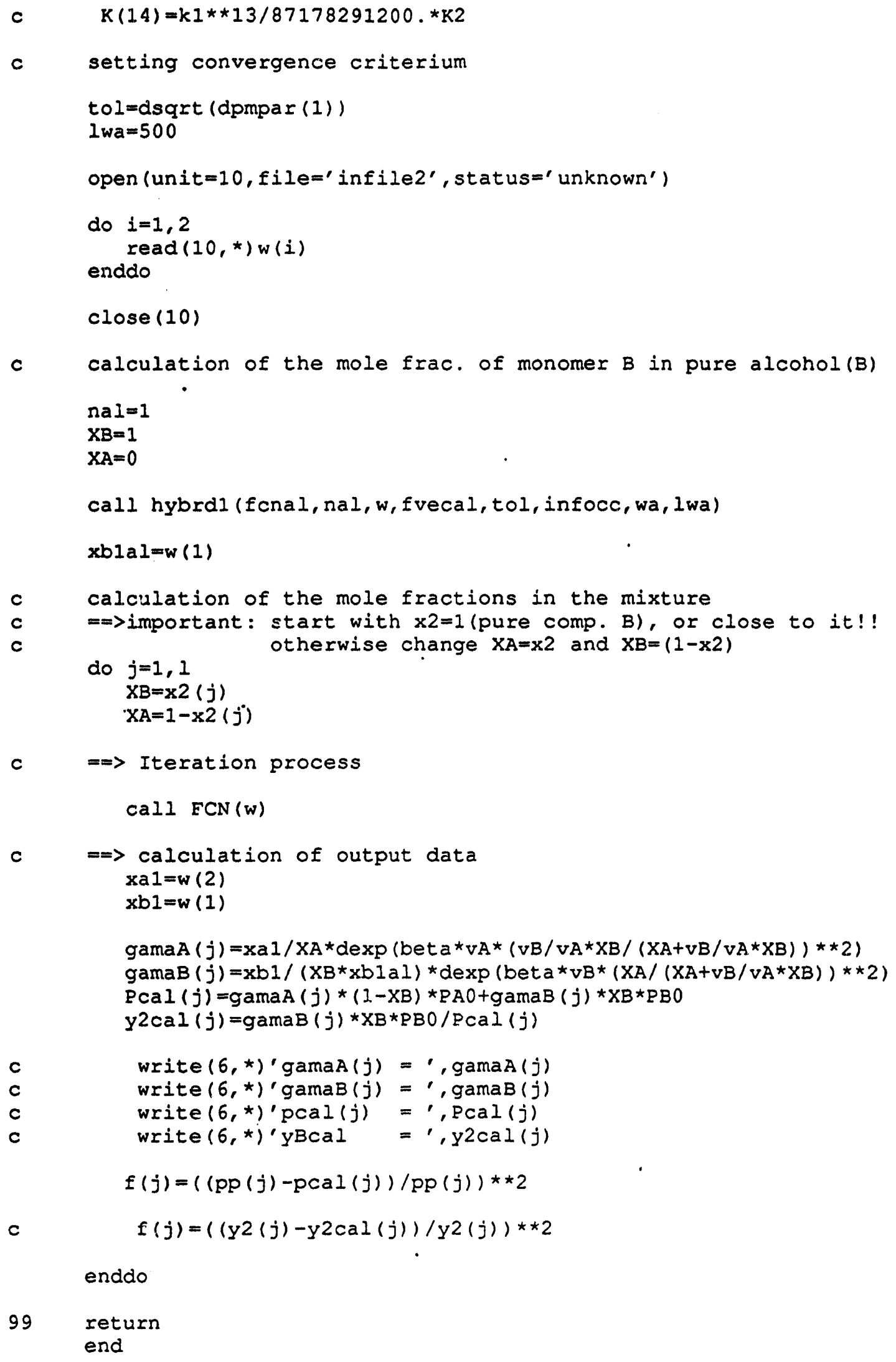


SUBROUTINE FCNAI (n,w, fvec, iflag)

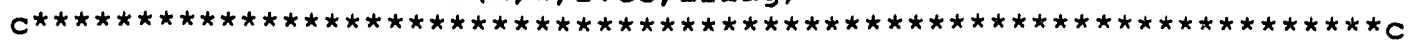

C

this subroutine contains the system of $n$ nonlinear

equations to calculate the true mole fraction of the

$i$-mers in pure alcohol B

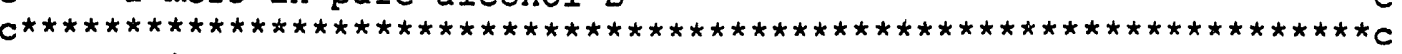

$w(i)=$ true mole fraction of $i$-mer $B, i=1,12$

$P(i)=$ product of chem. equlilibrium equations $(P(i)=w(i))$

$n=$ number of equations to be solved $(n=1)$

parameter $(\mathrm{ml}=100, \mathrm{nk}=12)$

implicit double precision $(a-h, 0-z)$

integer $n$, iflag

double precision $K(n k), w(n)$, fvec $(n), P(n k)$,

1

$X A, X B$

real sumwi

common/block5/K

common/block6/XA, XB

if $((x ! 1) .1 t .0) . o r .(w(1) . g t .1))$ then fvec $(1)=10000$

goto 99

endif

$P(2)=K(2){ }_{W}(1) \star \star 2$

$P(3)=K(3) * P(2) * W(1)$

$P(4)=K(4) * P(3) * W(1)$

$P(5)=K(5) * P(4) * W(1)$

$P(6)=K(6) \star P(5) \star w(1)$

$P(7)=K(7) \star P(6) * w(1)$

$P(8)=K(8) * P(7) * w(1)$

$P(9)=K(9) * P(8) * W(1)$

$P(10)=K(10) * P(9) * W(1)$

$P(11)=K(11) * P(10) * w(1)$

$P(12)=K(12) * P(11) * w(1)$

C $\quad \mathrm{P}(13)=\mathrm{K}(13) \star \mathrm{P}(12) \star \mathrm{w}(1)$

c $\quad \mathrm{P}(14)=\mathrm{K}(14) * \mathrm{P}(13) * \mathrm{~W}(1)$

sumwi=w(1)

do $I=2, n k$

sumw $i=$ sumw $i+P$ (I)

enddo

fvec (1)=XB-sumwi

99

return

end 


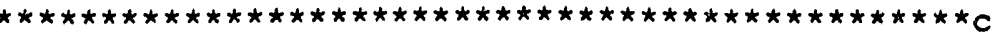

this subroutine contains the system of nonlinear

equations to calculate the true mole fraction of the

$n$-mers $B$ and the mole fraction of $A$, by starting at $X B=1$

with the value of $w(1)$ of pure alcohol $B$ and

searching for the next result for $w(1)$, by reducing

the value of $w$ (I) in very small steps.

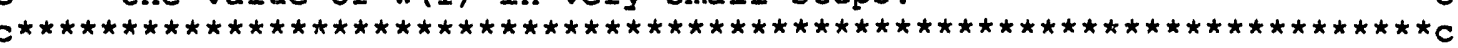

$w(1)=$ true mole fraction of monomer $B$

$w(2)=$ true mole fraction of monomer $A$

sump = sum of $P(i)$, (sum of the true mole fractions)

sumwi $=$ sum of $i * P(i)$

$K(i)=$ equilibrium constants of the association reaction

maxit $=$ maximum iteration cycles

$s=\operatorname{sign}$

parameter $(m l=100, n k=12)$

implicit double precision $(a-h, o-z)$

integer maxit

double precision $K(n k), w(2), P(n k), X A, X B$

real sumwi, sump, sump2

common $/ \mathrm{block} 5 / \mathrm{k}$

common/block $6 / \mathrm{XA}, \mathrm{XB}$

$p(1)=w(1)$

$\mathrm{P}(2)=K(2) \cdot * w(1) * * 2$

$P(3)=K(3) * P(2) * w(1)$

$P(4)=K(4) * P(3) * W(1)$

$P(5)=K(5) * P(4) \star W(1)$

$P(6)=K(6) * P(5) * W(1)$

$P(7)=K(7) \star P(6) * w(1)$

$P(8)=K(8) \star P(7) \star_{W}(1)$

$P(9)=K(9) * P(8) * W(1)$

$P(10)=K(10) * P(9) * w(1)$

$P(11)=K(11) * P(10) *_{W}(1)$

$P(12)=K(12) * P(11) * w(1)$

C $\quad P(13)=K(13) * P(12) * w(1)$

c $\quad \mathrm{P}(14)=\mathrm{K}(14) * \mathrm{P}(13){ }_{\mathrm{W}}(1)$

sump $=0$

do $i=1, n k$

sump $=$ sump $+P(i)$

enddo

sumwi $=0$

do $I=1, n k$

sumw $i=$ sumw $i+I * P(I)$

enddo

$w(2)=1-$ sump

fvec $=X B-($ sumwi $/($ sumwitw $(2)))$

100

step $=1.0 d-5$

$S=$ dsign $(1$, fvec $)$

$w(1)=w(1)$-step

$P(1)=W(1)$

$P(2)=K(2) * w(1) \star \star 2$

$P(3)=K(3) * P(2) * w(1)$

$\mathrm{P}(4)=\mathrm{K}(4) \star \mathrm{P}(3){ }^{\mathrm{W}}(1)$

$P(5)=K(5) * P(4) * W(1)$

$P(6)=K(6) * P(5) * W(1)$ 


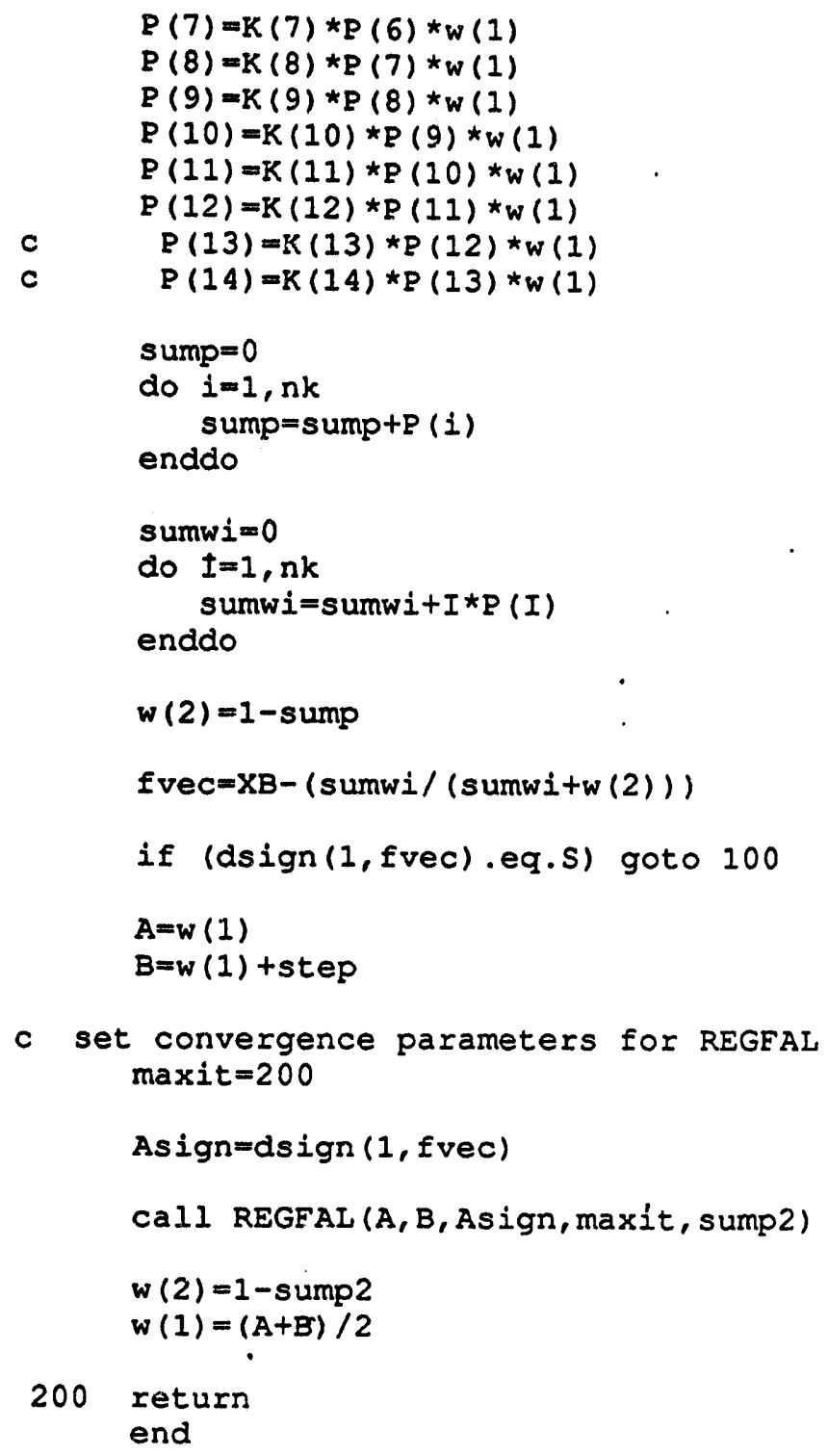


SUBROUTINE REGEAL (A, B, Asign, maxit, sump)

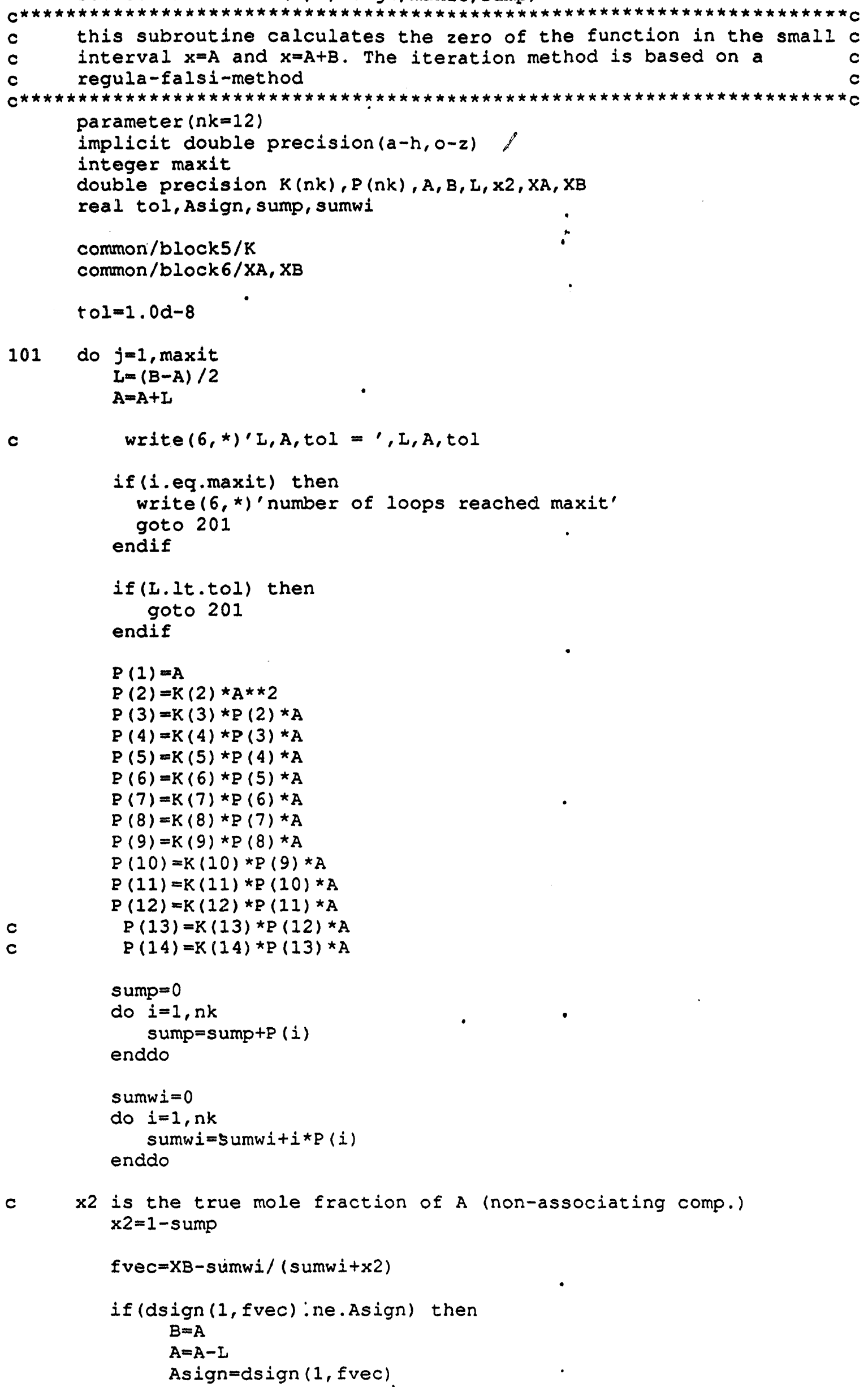




$$
\begin{aligned}
& \text { goto } 101 \\
& \text { else goto } 101 \\
& \text { endif } \\
& \text { enddo } \\
& 201 \text { return } \\
& \text { end }
\end{aligned}
$$


c System: n-Hexane (1)/Methylamin(2), $-40^{\prime} \mathrm{C}$, wolff and Hoepfner (1961)

POISSON-DISTRIBUTION MODEL

$k 1=5.320$ (Poisson distribution const.)
k2 $=1.767$ (dimerization const.)
beta $=199.864$ [cal/mol]
v1 $=2.79, \quad v 2=1.00$ (molar volumes)

Temperature $=233.0$ [K]

\begin{tabular}{rllll} 
P [mmHg] & x2 & y2 & P calc & y2 calc \\
\hline 126.00 & 0.9999 & 0.9999 & 126.29 & 0.9999 \\
125.30 & 0.9690 & 0.9900 & 124.44 & 0.9888 \\
122.60 & 0.9250 & 0.9810 & 122.35 & 0.9815 \\
121.60 & 0.8770 & 0.9780 & 120.87 & 0.9783 \\
120.10 & 0.8270 & 0.9760 & 119.98 & 0.9770 \\
119.20 & 0.7830 & 0.9760 & 119.56 & 0.9765 \\
118.90 & 0.7350 & 0.9750 & 119.31 & 0.9763 \\
117.70 & 0.6620 & 0.9750 & 119.05 & 0.9761 \\
117.90 & 0.6290 & 0.9750 & 118.90 & 0.9760 \\
116.70 & 0.5430 & 0.9750 & 118.18 & 0.9756 \\
115.20 & 0.4490 & 0.9740 & 116.49 & 0.9749 \\
113.60 & 0.3600 & 0.9730 & 113.44 & 0.9738 \\
109.10 & 0.2820 & 0.9720 & 108.97 & 0.9721 \\
103.90 & 0.2150 & 0.9700 & 102.90 & 0.9699 \\
99.20 & 0.1750 & 0.9680 & 97.60 & 0.9679 \\
89.50 & 0.1290 & 0.9640 & 88.79 & 0.9640 \\
74.80 & 0.0860 & 0.9560 & 75.43 & 0.9568 \\
63.70 & 0.0626 & 0.9470 & 64.02 & 0.9484 \\
48.70 & 0.0415 & 0.9310 & 49.29 & 0.9320 \\
36.10 & 0.0274 & 0.9060 & 36.28 & 0.9065 \\
23.20 & 0.0154 & 0.8510 & 23.06 & 0.8514 \\
12.60 & 0.0068 & 0.7220 & 12.47 & 0.7229 \\
3.60 & 0.0001 & 0.0370 & 3.61 & 0.0371 \\
& & & &
\end{tabular}

relative rms error vap pressure =

1. $64835 \mathrm{E}-03$

relative rms error mole fract. $\quad 1.92827 \mathrm{E}-04$ 
c System: n-Hexane (1)/Methylamin(2), $-40^{\prime} \mathrm{C}$, Wolfe and Hoepfner (1961)

0.3

$2.785 \quad 1.0$

6.01 .0

233

3.48

126.3

23

126.0

125.3

122.6

121.6

120.1

119.2

118.9

117.7

117.9

116.7

115.2

113.6

109.1

103.9

99.2

89.5

74.8

63.7

48.7

36.1

23.2

12.6

3.6

0.9999

0.969

0.925

0.877

0.827

0.783

0.735

0.662

0.629

0.543

0.449

0.360

0.282

0.215

0.175

0.129

0.086

0.0626

0.0415

0.0274

0.0154

0.0068

0.0001 beta

v1 v2

$k 1 \quad k 2$

Temperature in [K]

! 110

! 220

! number of data points

0.9999 ! P2 x2 y2

0.990

0.981

0.978

0.976

0.976

0.975

0.975

0.975

0.975

0.974

0.973

0.972

0.970

0.968

0.964

0.956

0.947

0.931

0.906

0.851

0.722

0.037 
OBJECTS=activ1.0 $\operatorname{act} 1 v 2.0 \operatorname{act} 1 v 3.0 \operatorname{act} 1 v 4.0 \operatorname{act} 1 v 5.01$

-

/home_b/MINPACK/LMDIE/enorm.0 I

/home_b/MINPACK/LMDIF/grfac.0 I

/home_b/MINPACK/LMDIE/dpmpar.o I

/home_b/MINPACK/LMDIF/fdjac2.0 I

/home-b/MINPACK/LMDIF/lmalf.0

/home_b/MINPACK/LMDIF/Impar.0

/home_b/MINPACK/LMDIF/grsolv.0 I

/home_b/MINPACK/HYBRD/dogleg.0 I

/home_b/MINPACK/HYBRD/fdjac1.0 I

/home_b/MINPACK/HYBRD/qform.0

/home b/MINPACK/HYBRD/rlmpyg o I

/home_b/MINPACK/HYBRD/rlupdt.o I

/home b/MINPACK/HYBRD/hybrd.o

hybrdi.o

activ: \$(OBJECTS)

$\$ 77$-O -O act.exe \$(OBJECTS)

makefile 
amin2.t

test $1 . \ln 2$

out

test 1. Info

run.ctl 

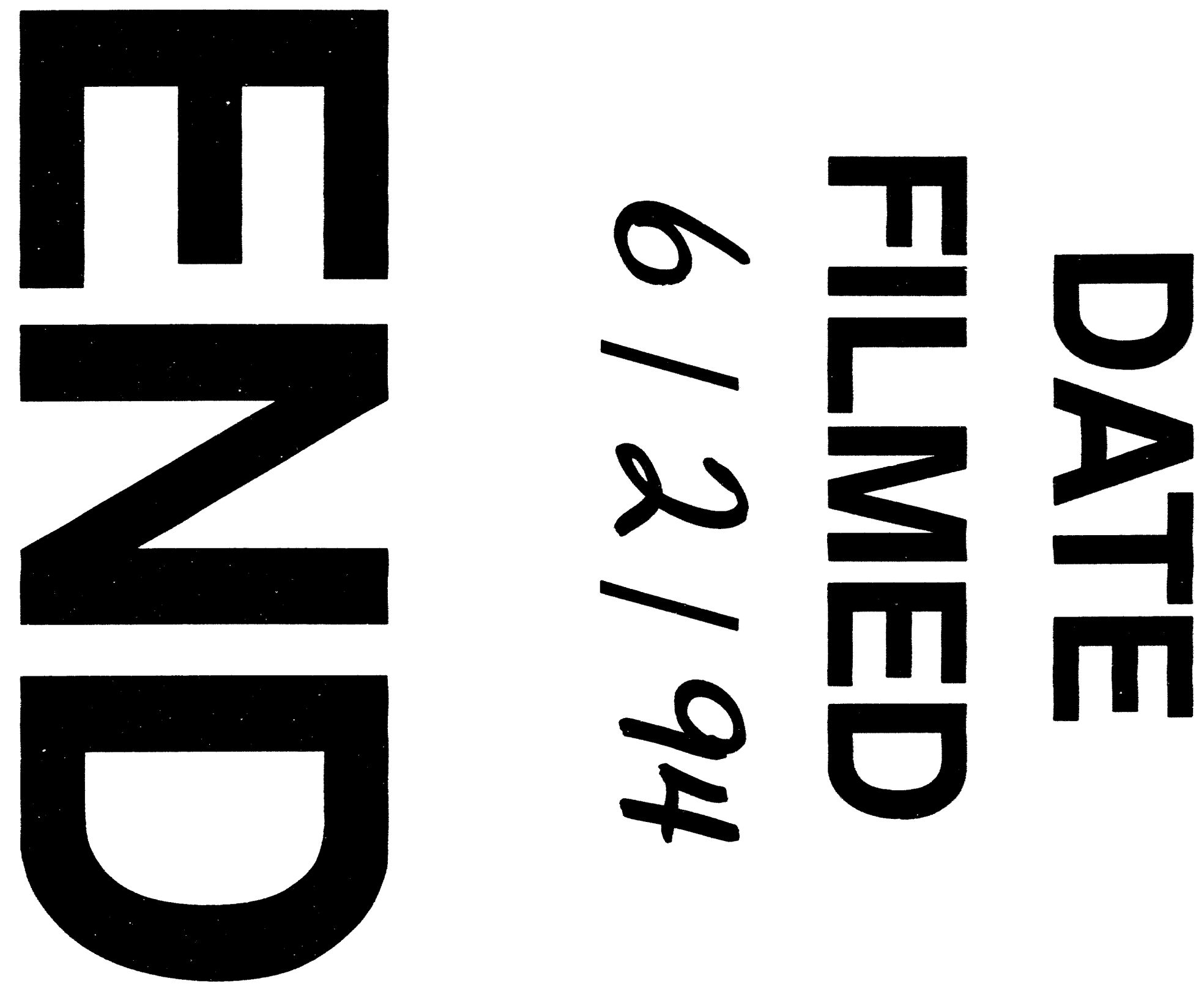
